\title{
Microcephaly and Chorioretinopathy, Autosomal Recessive, Type 1
}

National Cancer Institute

\section{Source}

National Cancer Institute. Microcephaly and Chorioretinopathy, Autosomal Recessive,

Type 1. NCI Thesaurus. Code C129306.

An autosomal recessive disorder caused by mutation(s) in the TUBGCP6 gene, encoding gamma-tubulin complex component 6 . It is characterized by microcephaly and chorioretinopathy. 